\title{
Cerrahi kanal dekompresyonu gerekli mi? Ne zaman ve nasıl?
}

\author{
Is surgical canal decompression necessary? \\ When and how?
}

\author{
Mutlu Çobanoğlu, Ali Şişman
}

Adnan Menderes Üniversitesi Tıp Fakültesi, Ortopedi ve Travmatoloji Anabilim Dalı, Aydın

Tüm omurga kırıkları ele alındığında, kırıkların en sık gözlendiği bölge torakolomber bölgedir. Genellikle yüksek enerjili travma sonucu görülen bu kırıklar oldukça ciddi yaralanmalardır. Bu bölge kırıklarının tedavisi uzun bir süredir tartışma konusudur. Tarihsel süreçte kimi yazar cerrahi olmayan tedavinin, kimi ise cerrahi tedavinin üstün olduğunu vurgulamıştır. Günümüzde tartışmanın yoğunlaştığı önemli noktalardan birisi de cerrahi kanal dekompresyonudur. Dekompresyonun hangi olgularda gerekli olduğu tartışması bir tarafa, uygulanma zamanı ve tekniği konusunda da tartışmalar sürmektedir. Literatüre bakıldığında erken cerrahi dekompresyon ve stabilizasyonun nörolojik iyileşmeyi artırdığı veya birkaç gün geciken cerrahinin nörolojik iyileşmeyi azalttığına dair kesin kanıtlar bulunmamaktadır. İlerleyici nörolojik arazın erken cerrahi için kesin endikasyon olduğu konusunda görüş birliği var iken, komplet veya statik inkomplet yaralanmalar konusunda fikir birliği yoktur. Bu konuda yapılan çalışmalarda ağırlıklı olarak 24 ve 72 saat sınır olarak kabul görmüştür. Her iki zaman diliminden önce gerçekleştirilen dekompresyonlarla da başarılı sonuçlar bildirilmiştir. Bu nedenle erken cerrahi için üst sınır 72 saat olarak kabul edilebilir. Posteriora yer değiştiren kırık parçaları tarafından basıya uğrayan nöral yapılar, indirekt ya da direkt cerrahi dekompresyon ile rahatlatılabilir. Indirekt redüksiyon ile oldukça başarılı sonuçlar bildirilmiştir. Ancak, karmaşık ve gecikmiş olgularda bu tekniği uygulamak mümkün olmamaktadır. Direkt dekompresyon anterior, posterior ve kombine yöntemler ile yapılabilir. Her tekniğin kendine göre avantajı ve dezavantajı olmakla birlikte, nörolojik iyileşme açısından herhangi birinin üstünlüğü gösterilememiştir. Ancak, daha kısa cerrahi süresi, daha az kan kaybı ve cerrahi tecrübenin daha fazla olması nedeni ile, posterior dekompresyon tercihi ön plana çıkmaktadır.

Anahtar sözcükler: torakolomber bölge kırıkları; nörolojik araz; dekompresyon
The most common site of spinal fractures is encountered at thoracolumbar region. These fractures which usually occur as a result of high energy traumas are serious injuries. Treatment of these fractures has been discussed for a long time. In the historical process, while some authors advocated advantage of non-surgical treatment, some others defended surgical treatment. Leaving aside the discussions on the issue of deciding in which cases surgical canal decompression is necessary, there is an ongoing debate on timing of surgery and surgical technique from the past to our time. There is not a definitive evidence that early surgical decompression and stabilization increases, or delayed surgery for a few days reduces neurological recovery. There is a consensus on early surgical intervention in case of progressive neurological deficit but it is controversial for complete or static incomplete injuries. The issue on surgical timing is accepted as a limit of 24 and 72 hours after injury. Successful results were reported with decompressions performed before both time periods. For this reason, the acceptable maximum time for early surgery can defined as 72 hours after the injury. Neural structures compressed by posteriorly displaced fragments can be relieved by indirect or direct decompression surgery. Successful results by indirect reduction through posterior instrumentation has been reported. But, this technique is not possible for complicated and delayed cases. Direct decompression can be performed via anterior, posterior, and combined methods. Each technique has own advantages and disadvantages. No one has superiority to each other in terms of neurological recovery. However, posterior decompression can be preferred because of the shorter duration of surgery, less blood loss, and greater surgical experience.

Key words: thoracolumbar region fractures; neurological damage; decompression

- Illetişim adresi: Doç. Dr. Mutlu Çobanoğlu, Adnan Menderes Üniversitesi Tıp Fakültesi Ortopedi ve Travmatoloji Anabilim Dalı, Aydın Tel: 04441256 / 3001 e-posta: drmutlu79@hotmail.com

- Gelis tarihi: 1 Kasım 2018 Kabul tarihi: 1 Kasım 2018 
O murga kırıkları sıklıkla torakolomber bölgede, özellikle de geçiş sahası olan T10-L2 arasında görülür. Bu geçiş sahasında sık yaralanma olmasının nedeni, kısmen daha hareketsiz olan torakal bölgeden, daha hareketli lomber bölgeye geçişte yüksek bir biyomekanik stresin meydana gelmesidir. ${ }^{[1]}$ Omurga kırıklarına spinal kord veya sinir kökü yaralanması eşlik edebilir.. ${ }^{[2]}$ Servikal omurga kırığı mevcut olgularda kısmi omurilik yaralanması daha sık iken, torakal bölgede meydana gelen yaralanmalarda omurilik hasarı daha az, ancak sıklıkla tam omurilik yaralanması şeklindedir. ${ }^{[3]}$ Torakolomber kırık ile başvuran hastaların spinal kord hasarı olup olmadığı, durumun ciddiyetini gösteren önemli bir unsurdur. ${ }^{[4]}$ Eğer nörolojik araz varlığında zamanında müdahale edilmezse kalıcı nörolojik hasar meydana gelebilir. ${ }^{[5]}$ Oluşabilecek nörolojik arazın yanında kronik ağrı, deformite ve fonksiyon kayıpları da ortaya çıkabilir. ${ }^{[6]}$ Bu bölgenin kırıkları, özellikle genç ve aktif bireylerde ciddi iş gücü kaybına, psikososyal travmalara neden olmaktadır. Hangi kırıkların cerrahi tedavi gerektirdiği ve hangi cerrahi yöntemin uygun olduğu tartışmaları halen devam etmektedir. Torakolomber omurga kırığı nedeni ile başvuran hastada tedavi planlarken, nörolojik arazın varlığı önemli bir kriterdir. Torakolomber bölge kırıklarında nörolojik arazı olan hastalarda konservatif tedavinin sonuçlarının iyi olduğu ve nörolojik iyileşme açısından cerrahinin konservatif tedaviye üstün olmadığı, yapısal nedenlerden cerrahi tedavi tercih edildiği bildirilmişse de, günümüzde torakolomber kırıkların tedavisinde nörolojik durumun seviyesi tedavi şeklinin kararını vermede önemli bir kriterdir. ${ }^{[7-10]}$ Nörolojik arazın eşlik ettiği torakolomber kırıkların cerrahi tedavisinde amaç; nöral elementleri dekomprese etmek, deformiteyi düzeltmek ve vertebral kolonu stabilize etmektir. ${ }^{[11]}$ Sonuç olarak; nörolojik araz varlığı ve stabil olmayan kırık varlığı, cerrahinin iki esas endikasyonu olarak kabul edilmektedir. ${ }^{[12,13]}$

\section{CERRAHI ZAMANLAMA NASIL OLMALI?}

Nörolojik arazın eşlik ettiği torakolomber yaralanmalarda, cerrahinin zamanlaması (erken veya geç) en önemli tartışma konularından biridir. Cerrahi zamanlama, yaralanmadan sonraki 72 saat içinde ise erken cerrahi, 72 saatten sonra ise geç cerrahi olarak tanımlanmaktadır. Torakal yaralanmalara önemli oranlarda akciğer kontüzyonu, kot kırığı (\%30), plevral effüzyon (\%39) ve pnömotoraks gibi akciğer problemleri eşlik eder. ${ }^{[14]}$ Lomber kırıklara ise önemli oranda pelvik yaralanmalar ${ }^{[15]}$, abdominal yaralanmalar ${ }^{[16]}$ ve sonuç olarak ciddi kan kaybı ${ }^{[17]}$ eşlik ettiği görülür. Bu nedenlerden dolayı, ameliyat zamanlamasını belirlemek oldukça güçtür. Ancak, erken cerrahinin de yaralanmaya bağlı ortaya çıkabilecek akciğer, böbrek ve beyin hasarlarını tetikleme ihtimali vardır. Erken cerrahide, oluşacak kan kaybını tolere etmek ve hipotansiyon ile mücadele de daha zor olacaktır. ${ }^{[18]}$ Cengiz ve ark.'nın, 27 hastanın dahil edildiği ileriye dönük çalışmalarında, ilk sekiz saat içinde ameliyat edilen (tespit ve dekompresyon) torakolomber kırıklı ve nörolojik arazı olan hastalarda, 3-15 gün arası ameliyat edilenlere göre nörolojik iyileşme ve komplikasyonlar açısından anlamlı üstünlük görülmektedir. ${ }^{[19]}$ Torakolomber omurga kırığı olan hastaların değerlendirildiği, ileriye dönük ve geniş katılımlı çalışmada, yaralanmadan sonraki 72 saat içinde ve 72 . saatten sonra cerrahi uygulanan olgular karşılaştırılmıştır. Erken cerrahi uygulananlarda komplikasyon açısından sonuçların daha iyi olduğu belirtilmiştir. Ancak, kritik durumda olan hastalarda, cerrahiyi ertelemek gerektiği de vurgulanmıştır. ${ }^{[20,21]}$ Bourassa-Moreau ve ark., omurilik yaralanması eşlik eden ve yaralanmadan sonraki ilk 24 saat içinde ve 24 . saat sonrası yapılan dekompresyon sonuçları değerlendirilen, 33'ü torakolomber, 20'si servikal omurga kırığı olan olgularından, erken cerrahi uygulananlarda nörolojik iyileşmenin daha hızlı olduğunu bildirdiler. ${ }^{[22]}$ Deneysel bir çalışmada da, erken dekompresyonun spinal kord hasarının patolojik olarak iyileşmesi üzerinde olumlu etkileri gösterilmiştir. ${ }^{[23]}$ Genel olarak erken cerrahinin nörolojik iyileşme üzerine olumlu etkileri olduğu konusunda fikir birliği olsa da, genel durumu kritik ve cerrahide riski çok yüksek hastalarda, genel durumun cerrahiye hazır hale gelmesini beklemek daha akıllıca olacaktır. Ayrıca, özellikle torakal omurga kırığı varlığında; hastane, yoğun bakımda kalış ve ventilatöre bağlı kalma sürelerini, hastane giderlerini, morbiditeyi veya potansiyel mortaliteyi azaltmak için 72 saatten önce cerrahi uygulama önerilmektedir. ${ }^{[21,24]}$

\section{CERRAHI DEKOMPRESYON GEREKLI Mİ?}

İlerleyici nörolojik arazın erken cerrahi için kesin endikasyon olduğu konusunda görüş birliği var iken, komplet veya statik inkomplet yaralanmalar konusunda bu birlik yoktur. Nörolojik arazı olan bir hastanın cerrahi tedavisinde kanal dekompresyonu gerekliliği, hangi teknik ve yaklaşım uygulanacağı da diğer bir tartışma konusudur. Nörolojik arazın yaralanma anında meydana geldiği ve sonraki görüntülemede kırık parçalarının pozisyonu ile ilgili olmadığı gösterilmiştir. ${ }^{[7]}$ Kanalın daralması ile nörolojik araz arasında anlamlı bir ilişki olduğu belirtilmesine rağmen, darlığın miktarı ile arazın şiddeti ilişkilendirilememiştir. ${ }^{[25,26]}$ Dolayısıyla, nörolojik arazın varlığında kanal daralmasının şiddetine göre dekompresyon yöntemine karar vermek güçtür. 
Cerrahi olarak farklı dekompresyon teknikleri ve yaklaşım şekilleri tanımlanmıştır. Kanal dekompresyonu direkt ya da indirekt yol ile gerçekleştirilebilir. İndirekt dekompresyon posterior enstrümantasyon yoluyla; distraksiyon yaparak, kifozu düzelterek veya ligamentotaksis yoluyla sağlanabilir. (Şekil 1) Ayrıca, ilk 12 ay içinde kanalın hızlıca remodele olabileceği konusunda fikir birliği mevcuttur (Şekil 2). ${ }^{[8,27]}$ Direkt dekompresyon, posterior girişim ile sağlanan posterolateral dekompresyon (Şekil 3) ve anterior ya da posterior girişim ile parsiyel veya total vertebra cismi rezeksiyonu yaparak dekompresyon sağlamaktır (Şekil 4). ${ }^{[28]}$ Her iki yöntemin de kendine özgü avantaj ve dezavantajları olmakla birlikte, ihtiyaca göre
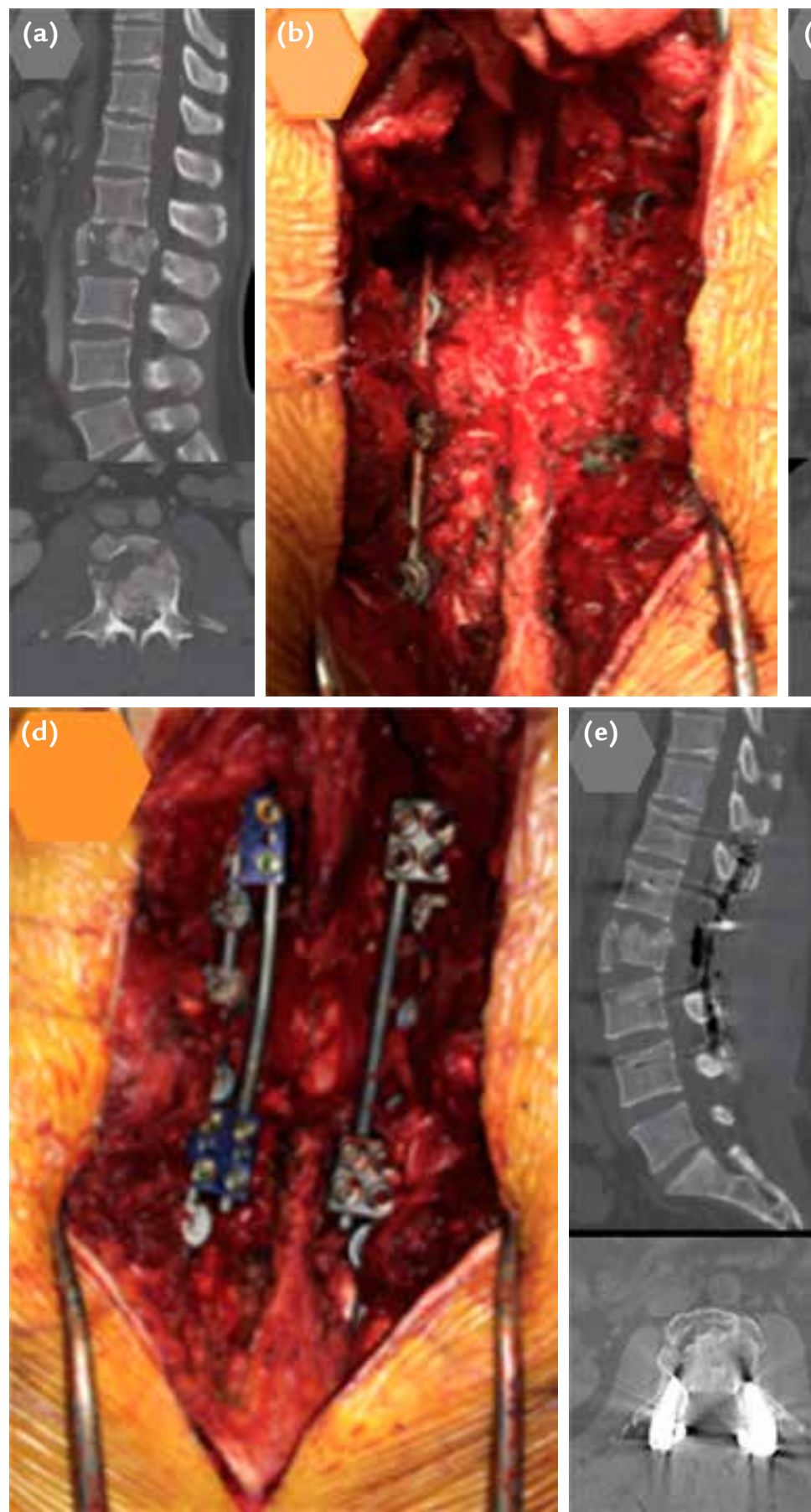
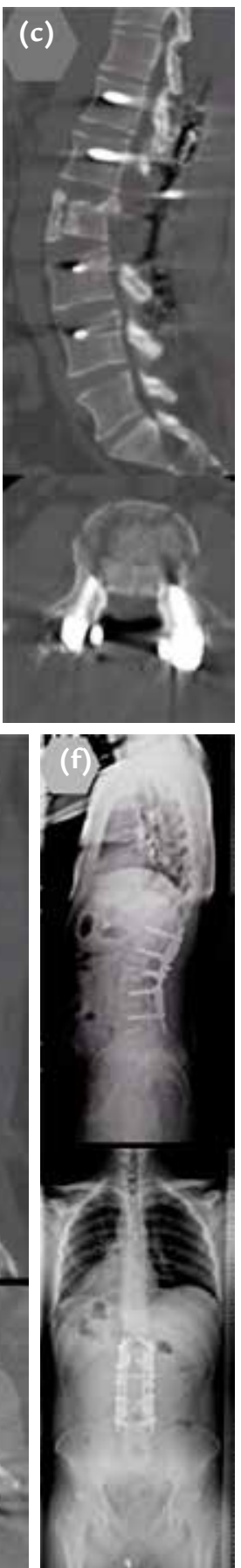

Şekil 1. a-f. Erkek; 37 yaş; yüksekten düşme sonrası L2 burst kırığ, Sağ alt ekstremitede inkomplet nörolojik defisit, T12-L4 posterior enstrümantasyon, füzyon, L2 laminektomi ile direkt posterior dekompresyon uygulanan ve dizilimin sağlanması ile elde edilen indirekt dekompresyonun uygulandığı olgunun; ameliyat öncesi sagittal ve aksiyel bilgisayarlı tomografi (BT) kesitlerinde kanalda daralma olduğu (a); kırığa bağlı oluşan dura hasarının görüldüğü ameliyat sırasındaki görüntüsü (b); ameliyattan sonra çekilen BT'de dekompresyon ve dizilimin düzeltilmesi ile sağlanan kanal dekompresyonu (c); ameliyat sonrası dura onarımının ve enstrümantasyonun ameliyat içi görüntüsü (d); ameliyatın 15. ay BT kesitlerde kırıkta kaynama ve omurga yüksekliğinin korunduğu (e); ameliyatın 15. ay lateral ve PA grafisinde dizilimin korunduğu (f) görülmektedir. 

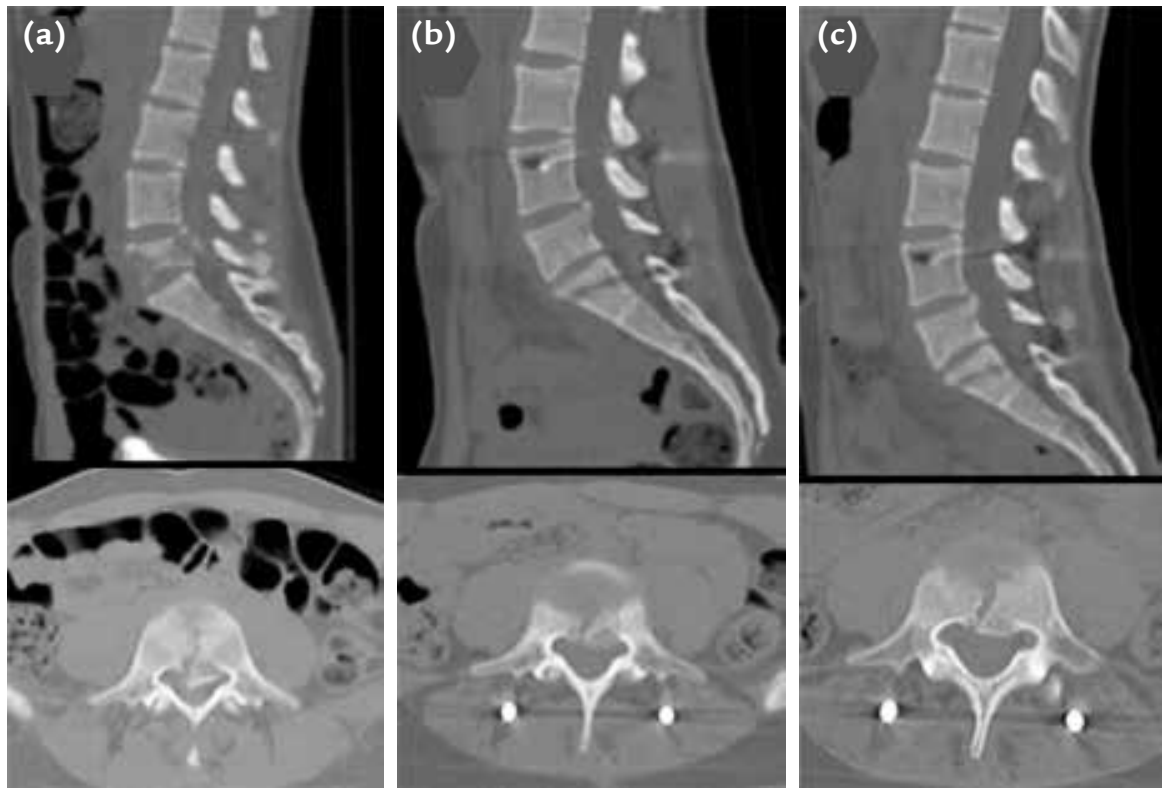

Şekil 2. a-c. Kadın; 18 yaş; yüksekten düşme sonrası L5 burst kırığı. Sol alt ekstremitede inkomplet kök hasarı bulguları mevcut. L4-S1 posterior enstrümantasyon uygulanan olgunun; ameliyat öncesi sagittal ve aksiyel BT kesitlerinde kanalın özellikle sol tarafını daraltan kemik parça olduğu (a); ameliyatın 3. ay (b) ve 12. ay (c) BT kesitlerde kırıkta kaynama ve spinal kanalda yeniden şekillenme olduğu görülmektedir. Klinik bulgular ameliyattan sonraki ilk dört ay içinde tamamen geriledi.
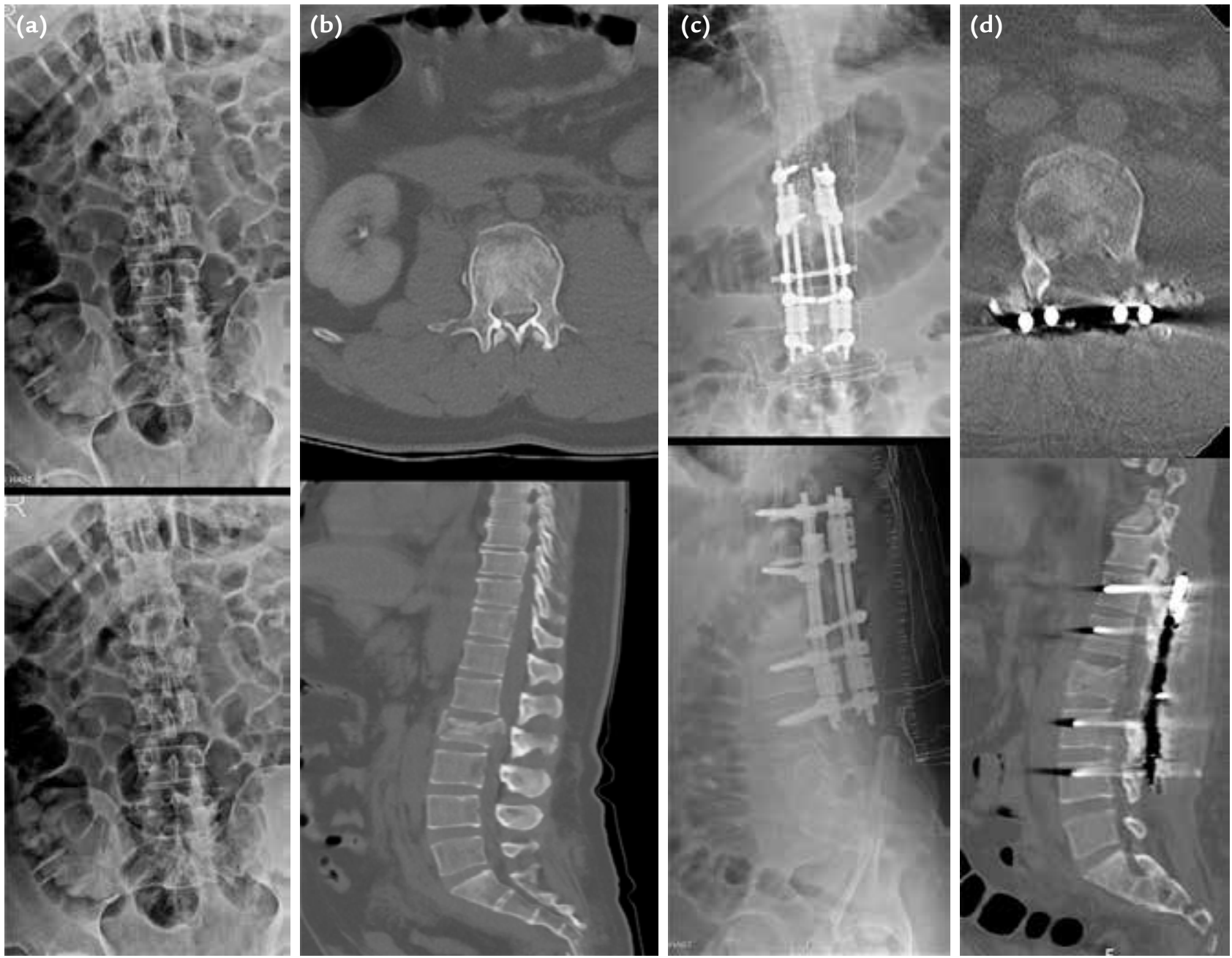

Şekil 3. a-d. Erkek; 42 yaşında; araç içi trafik kazası, L2 vertebra fraktürü ve inkomplet nörolojik arazı mevcut. Ameliyat öncesi lateral ve ön-arka grafileri (a); ameliyat öncesi BT kesitleri (b). Posterior enstrümantasyon ve posterolateral dekompresyon yapıldı. Ameliyat sonrası lateral ve AP grafileri (c); ameliyat sonrası BT kesitleri (d). Posteriora deplase kırık parçanın redüksiyonu görülmektedir. 


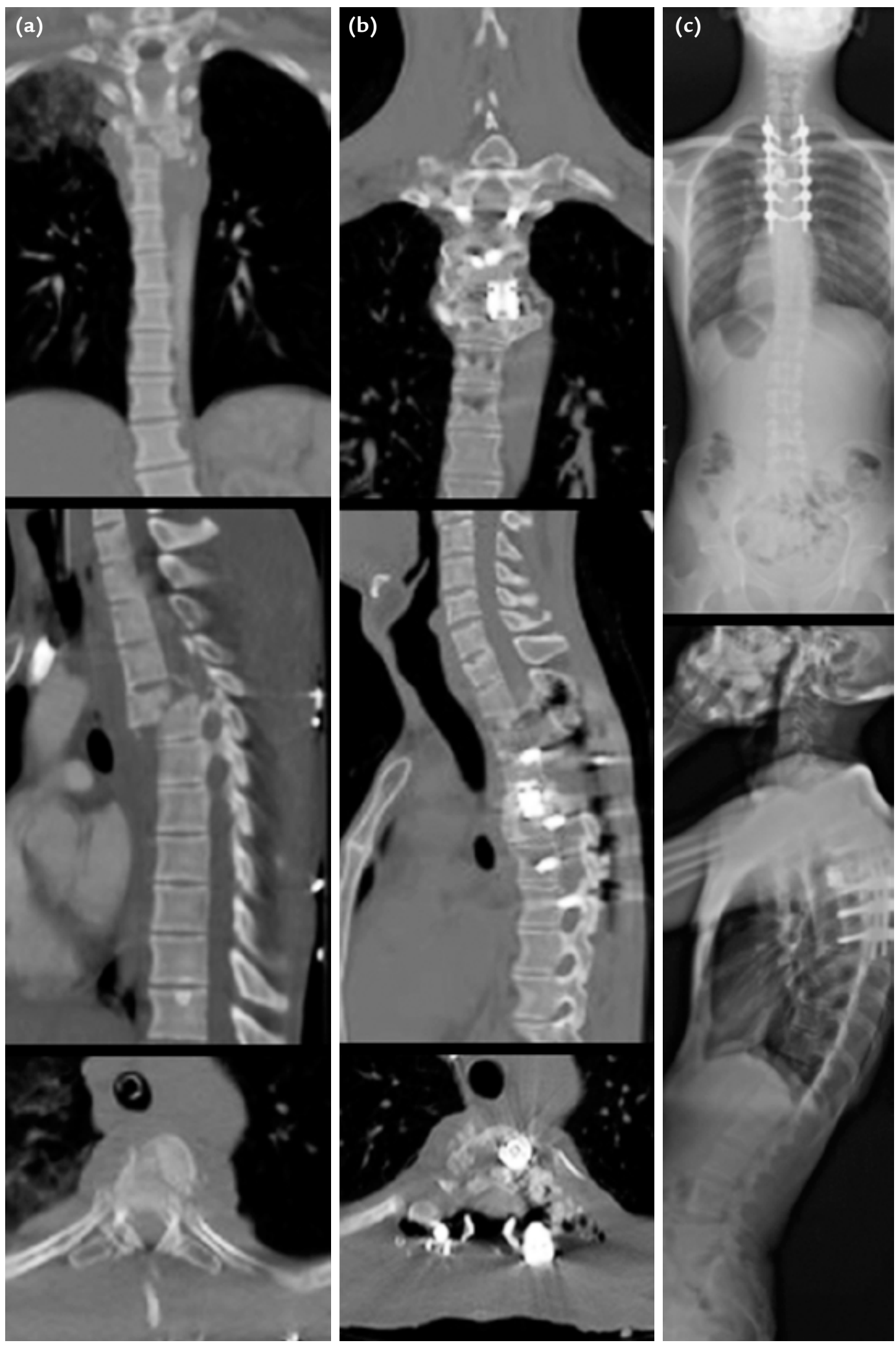

Şekil 4. a-c. Erkek, 23 yaş, motosiklet kazası sonrası T4 kırıklı-çıkığı ve yaralanma seviyesinin altında inkomplet nörolojik defisit mevcut olguya posterior yaklaşım ile parsiyel korpektomi uygulandı. Ameliyat öncesi sagittal, koronal ve aksiyel BT kesitlerinde T4'ün anterolaterale yer değiştirdiği (a); ameliyat sonrası 12. ay sagittal, koronal ve aksiyel BT kesitlerde ameliyat sonrası elde edilen redüksiyonun korunduğu, kaynama olduğu (b); ameliyat sonrası 12. ay lateral ve PA grafisinde omurganın dengede olduğu (c) görülmektedir. 
ve dekomprese edilecek alana göre posterior ya da anterolateral yaklaşım tercih edilebilir. ${ }^{[29,30]}$ Anterior yaklaşımın morbid obezlerde zorluk oluşturması ve pulmoner yapıları tehlikeye atması dezavantaj iken, tüm nöral yapıların dekompresyonuna izin vermesi ve eş zamanlı anterior kolon desteğini sağlayabilmesi avantajlarıdır. Günümüzde yaygın olarak tercih edilen yöntem posterior yaklaşım olmakla birlikte, ciddi kanal içi kemik parça içeren olgularda anterior girişim tercih edilmektedir. ${ }^{[31]}$ Posterior yaklaşımın daha az kan kaybı ve daha az ameliyat süresinin yanında, spinal kanalın tamamına $360^{\circ}$ hakim olunabilen iyi bir görüş alanı sağladığı, anterior yaklaşıma göre daha etkin bir dekompresyon elde edildiğini belirten yayınlar da vardır. ${ }^{[32,33]}$ Torakolomber burst tarzı kırıkları olan olgularda anterior ve posterior yaklaşım ile subtotal korpektomi, kanal dekompresyonu ve rekonstrüksiyon karşılaştırıldığında; posterior yaklaşımın komplikasyon oranı, cerrahi süresi ve kan kaybı açısından daha avantajlı olduğu, nörolojik iyileşme açısından da bu iki yaklaşımın aralarında fark olmadığı belirtilmektedir. ${ }^{[3,34]}$ Liu ve ark. stabil olmayan torakolomber kırığı olan 39 olguda posterior yaklaşımla yapılan dekompresyon ve üç kolon rekonstrüksiyonu ile, sinir iyileşmesi bakımından oldukça tatmin edici sonuçlar elde etmişler ve bunun stabil olmayan torakolomber kırıklarda en iyi yaklaşımlardan biri olduğunu belirtmişlerdir. ${ }^{[34,35]}$ Posterior enstrümantasyonla beraber dekompresyon yapılan olgular ile, posterior enstrümantasyonla anterior kompresyonun kombine uygulandığı iki grubu kıyaslayan çalışmada, nörolojik iyileşme açısından aralarında anlamlı bir fark olmadığı belirtilmiştir. Yine bu çalışmada, posterior dekompresyonda iyileşmeyi sağlayan gerçek nedenin, dekompresyonun direkt mi yoksa indirekt mi uygulanması olduğu net olarak anlaşılamamıştır. Yine, ciddi kanal basısı varlığında kombine anterior-posterior (AP) yaklaşımı önermişlerdir. ${ }^{[31]}$ Bunun dışında son yıllarda, torakoskopik cerrahi yöntemlerin torakolomber bölge kırıklarının cerrahi tedavisinde de kullanımı yaygınlaşmaya başlamıştır. Torakolomber bölge kırı̆gı olan hastalara minimal invaziv torakoskopik yöntem ile anterior dekompresyon yapılan olgularda başarılı sonuçlar bildiren çalışmalar bulunmaktadır. ${ }^{[36]}$

Nörolojik arazın bulunduğu torakolomber kırıklarda erken cerrahinin süresi hakkında net bir fikir birliği oluşmamış olup, olgunun tercihen yaralanmadan sonraki ilk 72 saat içinde veya genel durumunun müsaade ettiği erken dönemde, cerrahın cerrahi tekniklerdeki tecrübesi ve nörolojik arazın derecesi göz önünde bulundurularak, kanal dekompresyonu ve omurga stabilizasyonu uygun yaklaşım olacaktır.

\section{KAYNAKLAR}

1. Re: Kirkham B. Wood, Weishi Li, Darren S. Lebl, Avraam Ploumis. Management of thoracolumbar spine fractures. Spine J 2014;1:145-64. Spine J 2014;14(8):A18. Crossref

2. Burney RE, Maio RF, Maynard F, Karunas R. Incidence, characteristics, and outcome of spinal cord injury at trauma centers in North America. Arch Surg 1993;128(5):596-9. Crossref

3. Tator CH, Duncan EG, Edmonds VE, Lapczak LI, Andrews DF. Neurological recovery, mortality and length of stay after acute spinal cord injury associated with changes in management. Paraplegia 1995;33(5):254-62. Crossref

4. Gasbarrini A, Li H, Cappuccio M, Mirabile L, Paderni S, Terzi $S$, Boriani S. Efficacy evaluation of a new treatment algorithm for spinal metastases. Spine 2010;35(15):1466-70. Crossref

5. Cui H, Guo J, Yang L, Guo Y, Guo M. Comparison of therapeutic effects of anterior decompression and posterior decompression on thoracolumbar spine fracture complicated with spinal nerve injury. PakJ Med Sci Q 2015;31(2):346-50. Crossref

6. Diaz JJ Jr, Cullinane DC, Altman DT, Bokhari F, Cheng JS, Como J, Gunter O, Holevar M, Jerome R, Kurek SJ, Lorenzo M, Mejia V, Miglietta M, PJ O'Neill, Rhee P, Sing R, Streib E, VaslefS. Practice management guidelines for the screening of thoracolumbar spine fracture. J Trauma 2007;63(3):709-18. Crossref

7. Boerger TO, Limb D, Dickson RA. Does "Canal Clearance" Affect Neurological Outcome After Thoracolumbar Burst Fractures? J Bone Joint Surg Br 2000;82-B(5):629-35. Crossref

8. Mohanty SP, Venkatram N. Does neurological recovery in thoracolumbar and lumbar burst fractures depend on the extent of canal compromise? Spinal Cord 2002;40(6):295-9. Crossref

9. Weninger $\mathrm{P}$, Schultz $\mathrm{A}$, Hertz $\mathrm{H}$. Conservative management of thoracolumbar and lumbar spine compression and burst fractures: functional and radiographic outcomes in 136 cases treated by closed reduction and casting. Arch Orthop Trauma Surg 2009;129(2):207-19. Crossref

10. Joaquim AF, de Almeida Bastos DC, Jorge Torres $\mathrm{HH}$, Patel AA. Thoracolumbar Injury Classification and Injury Severity Score System: A Literature Review of Its Safety. Global Spine J 2016;6(1):80-5. Crossref

11. Panjabi MM, Kato $\mathrm{Y}$, Hoffman $\mathrm{H}$, Cholewicki J. Canal and Intervertebral Foramen Encroachments of a Burst Fracture. Spine 2001;26(11):1231-7. Crossref

12. Bohlman $\mathrm{HH}$. Treatment of fractures and dislocations of the thoracic and lumbar spine. J Bone Joint Surg Am 1985;67(1):165-9. Crossref

13. Weinstein JN, Collalto P, Lehmann TR. Thoracolumbar "Burst" Fractures Treated Conservatively: A Long-Term Follow-up. Spine 1988;13(1):33-8. Crossref

14. Lemburg SP, Frangen TM, Knoop H, Nicolas V, Heyer CM. Prognostic pulmonary and thoracic findings in patients with unstable injuries of the thoracic spine. Pneumologie 2011;65(7):412-8. Crossref

15. Pouw $M H$, Deunk J, Brink M, Dekker HM, Kool DR, Vugt $A B$, Edwards MJR. Is a pelvic fracture a predictor for thoracolumbar spine fractures after blunt trauma? J Trauma 2009;67(5):1027-32. Crossref

16. Xia T, Tian JW, Dong SH, Wang L, Zhao QH. Non-spinalassociated injuries with lumbar transverse process fractures: influence of segments, amount, and concomitant vertebral fractures. J Trauma Acute Care Surg 2013;74(4):1108-11. Crossref 
17. Vallier HA, Super DM, Moore TA, Wilber JH. Do patients with multiple system injury benefit from early fixation of unstable axial fractures? The effects of timing of surgery on initial hospital course. J Orthop Trauma 2013;27(7):405-12. Crossref

18. Kato S, Murray JC, Kwon BK, Schroeder GD, Vaccaro AR, Fehlings MG. Does Surgical Intervention or Timing of Surgery Have an Effect on Neurological Recovery in the Setting of a Thoracolumbar Burst Fracture? J Orthop Trauma 2017;31:S38-43. Crossref

19. Cengiz SL, Kalkan E, Bayir A, llik K, Basefer A. Timing of thoracolomber spine stabilization in trauma patients; impact on neurological outcome and clinical course. A real prospective $(\mathrm{rct})$ randomized controlled study. Arch Orthop Trauma Surg 2008;128(9):959-66. Crossref

20. Bliemel C, Lefering R, Buecking B, Frink M, Struewer J, Krueger A, Ruchholtz S, Frangen TM. Early or delayed stabilization in severely injured patients with spinal fractures? Current surgical objectivity according to the Trauma Registry of DGU. J Trauma Acute Care Surg 2014;76(2):366-73. Crossref

21. Xing D, Chen $Y$, Ma JX, Song DH, Wang J, Yang Y, Feng R, Lu $\mathrm{J}$, Ma XL. A methodological systematic review of early versus late stabilization of thoracolumbar spine fractures. Eur Spine J 2013;22(10):2157-66. Crossref

22. Bourassa-Moreau É, Mac-Thiong JM, Li A, Feldman DE, Gagnon DH, Thompson C, Parent S. Do Patients with Complete Spinal Cord Injury Benefit from Early Surgical Decompression? Analysis of Neurological Improvement in a Prospective Cohort Study. J Neurotrauma 2016;33(3):301-6. Crossref

23. Batchelor PE, Wills TE, Skeers P, Battistuzzo CR, Macleod MR, Howells DW, Sena ES. Meta-analysis of pre-clinical studies of early decompression in acute spinal cord injury: a battle of time and pressure. PLoS One 2013;8(8):e72659. Crossref

24. Kerwin AJ, Griffen MM, Tepas JJ 3rd, Schinco MA, Devin $T$, Frykberg ER. Best practice determination of timing of spinal fracture fixation as defined by analysis of the National Trauma Data Bank. J Trauma 2008;65(4):824-31. Crossref

25. Lemons VR, Wagner FC Jr, Montesano PX. Management of thoracolumbar fractures with accompanying neurological injury. Neurosurgery 1992;30(5):667-71. Crossref

26. Fontijne WP, de Klerk LW, Braakman R, Stijnen T, Tanghe HL, Steenbeek R, van Linge B. CT scan prediction of neurological deficit in thoracolumbar burst fractures. J Bone Joint Surg Br 1992;74-B(5):683-5. Crossref
27. Yazıcı M, Atilla B, Tepe S, Çalısıır A. Spinal Canal Remodeling in Burst Fractures of the Thoracolumbar Spine. J Spinal Disord 1996;9(5):409-13. Crossref

28. Kaneda K, Taneichi H, Abumi K, Hashimoto T, Satoh S, Fujiya M. Anterior Decompression and Stabilization with the Kaneda Device for Thoracolumbar Burst Fractures Associated with Neurological Deficits. J Bone Joint Surg Am 1997;79(1):69-83. Crossref

29. Dai LY, Jiang LS, Jiang SD. Posterior short-segment fixation with or without fusion for thoracolumbar burst fractures: a five to seven-year prospective randomized study. J Bone Joint Surg Am 2009;91(5):1033-41. Crossref

30. Dai LY, Jiang LS, Jiang SD. Anterior-only stabilization using plating with bone structural autograft versus titanium mesh cages for two- or three-column thoracolumbar burst fractures: a prospective randomized study. Spine 2009;34(14):142935. Crossref

31. Shin JK, Goh TS, Son SM, Lee JS. Treatment of Thoracolumbar and Lumbar Unstable Burst Fractures by Using Combined and Posterior Surgery. J Trauma Injury 2016;29(1):14-21. Crossref

32. Wu LY, Huang XM, Wang $Y$, Yang ZB, Su SH, Wang C. Posterior spinal canal decompression with screw fixation and reconstruction of three vertebral column for thoracolumbar burst fractures complicated with nerve injury. Zhongguo Gu Shang 2018;31(4):322-7. Crossref

33. Zhu Q, Shi F, Cai W, Bai J, Fan J, Yang H. Comparison of Anterior Versus Posterior Approach in the Treatment of Thoracolumbar Fractures: A Systematic Review. Int Surg 2015;100(6):1124-33. Crossref

34. Lin B, Chen ZW, Guo ZM, Liu H, Yi ZK. Anterior Approach Versus Posterior Approach With Subtotal Corpectomy, Decompression, and Reconstruction of Spine in the Treatment of Thoracolumbar Burst Fractures: A Prospective Randomized Controlled Study. J Spinal Disord Tech 2011. Crossref

35. Liu Z, Ke Z, Chen L, Yan Z, Chen F, Deng Z. Anterolateral decompression and three column reconstruction through posterior approach for treatment of unstable thoracolumbar fracture. Zhongguo Xiu Fu Chong Jian Wai Ke Za Zhi 2013;27(7):824-8.

36. Kocis J, Kelbl M, Wendsche P, Vesely R. Minimally invasive thoracoscopic approach to thoracolumbar junction fractures. Biomed Pap Med Fac Univ Palacky Olomouc Czech Repub 2016;160(4):566-70. Crossref 